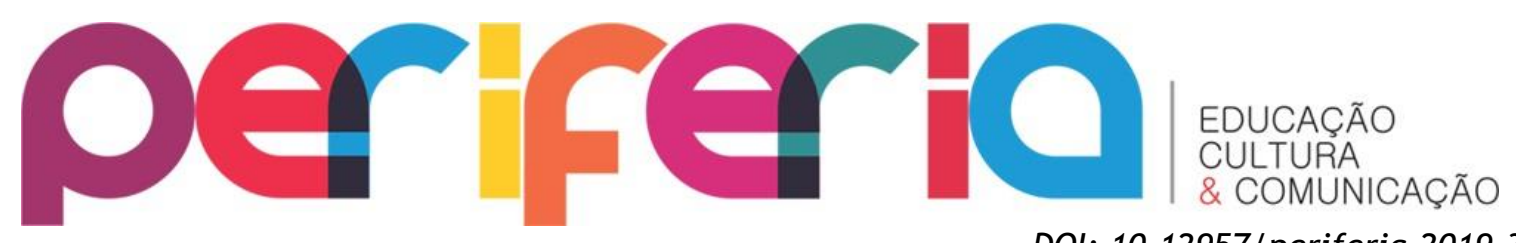

DOI: 10.12957/periferia.2019.34455

\title{
ONGs: PRÁTICA CIDADÃ OU OMISSÃO DE UM ESTADO REGULADOR?
}

\author{
Cíntia Borges de Almeida ${ }^{1}$ \\ Universidade Estadual de Santa Cruz - UESC-BA \\ Giselle Rafael de Lima \\ Faculdade Fernanda Bicchieri - FABEL - Belford Roxo
}

\section{Resumo}

Este trabalho tem como objetivo problematizar a historicidade das Organizações não governamentais (ONGs) no Brasil, assim como analisar suas contribuições sociais e suas práticas pedagógicas no que diz respeito aos espaços de educação não formal. Nesta direção, como operação metodológica foram feitas análises de aportes teóricos a partir de estudos voltados ao percurso das ONGs nacionais e ao papel desempenhado socialmente por essas instituições, assim como, análise de pesquisas que investigam a atuação das ONGs em espaços educativos de forma dissociada de cenários escolares, promovendo, ainda assim, um ambiente formador. Com esta empreitada justifica-se a escolha do objeto de estudo acreditando ser um tema relevante, já que é possível questionar a transferência estatal da responsabilidade estatal sob uma concepção de Estado Regulador (BARROSO, 2005), observando, deste modo, o processo histórico de atuação dessas instituições, seus objetivos principais em cada contexto, além de apresentar a discussão em torno dos diferentes espaços de formação, sejam eles formais ou informais, escolares ou extra-escolares (GOHN, 2013). Conclui-se que as Organizações não Governamentais atuam em variados espaços com objetivos específicos e que, apesar de desempenharem um importante papel social, essas instituições não devem diminuir o papel e o compromisso do Estado com as políticas educacionais públicas.

Palavras-chave: ONGs; educação informal; práticas pedagógicas; estado; sociedade

\footnotetext{
${ }^{1}$ Doutora em Educação - ProPEd, pela Universidade do Estado do Rio de Janeiro (UERJ). Professora da Universidade Estadual de Santa Cruz/ UESC- BA, pelo Departamento de Ciências da Educação. Professora da Faculdade Fernanda Bicchieri/ FABEL - Belford Roxo, na Licenciatura em Pedagogia e na Pós-Graduação em Gestão Integrada da Educação. cintiaborgesalmeida@yahoo.com.br

2 Pedagoga formada pela Faculdade Fernanda Bicchieri/ FABEL - Belford Roxo. gisellerafaellima@gmail.com
} 


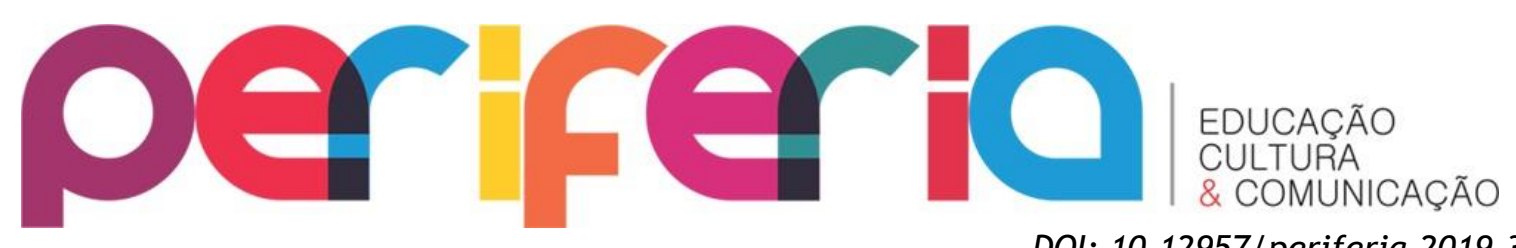

DOI: 10.12957/periferia.2019.34455

\title{
ONGs: CITIZEN PRACTICE OR OMISSION OF A REGULATORY STATE?
}

\begin{abstract}
This paper aims to problematize the historicity of non - governmental Organizations (ONGs) in Brazil, as well as to analyze their social contributions and their pedagogical practices regarding non - formal education spaces. In this direction, as a methodological operation, analyzes of theoretical contributions were made based on studies focused on the trajectory of national ONGs and on the social role played by these institutions, as well as the analysis of research that investigated the role of ONGs in educational spaces in a way that is dissociated from school scenarios, while promoting a training environment. With this undertaking, it is justified the choice of the study object, believing it to be a relevant topic, since it is possible to question the state transference of state responsibility under a conception of Regulatory State (BARROSO, 2005), so that observe the historical process of these institutions, their main objectives in each context, and present the discussion about the different spaces of formation, whether formal or informal, school or non-school (GOHN, 2013). Concludes that non-governmental organizations operate in a variety of spaces with specific objectives and that, although they play an important social role, these institutions should not diminish the role and commitment of the state to public education policies.
\end{abstract}

Keywords: ONGs; Informal education; Pedagogical practices; State; Society. 


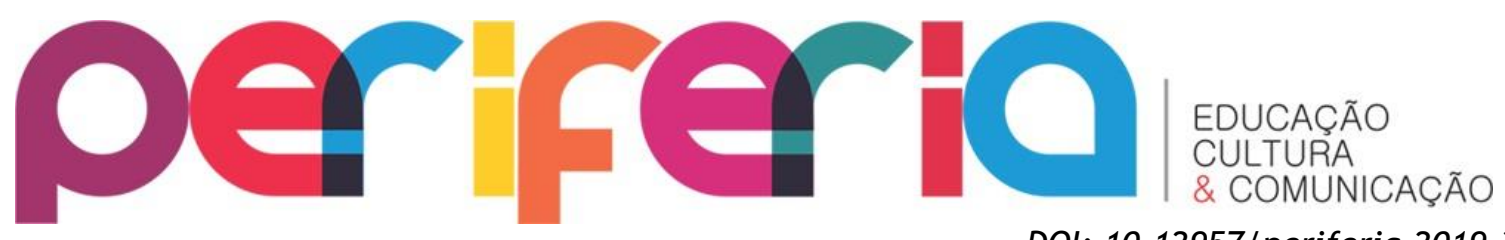

DOI: $10.12957 /$ periferia.2019.34455

\section{ONGs: PRÁCTICA CIUDADANA O OMISIÓN DE UN ESTADO REGULADOR?}

\section{Resumen}

Este trabajo tiene como objetivo problematizar la historicidad de las Organizaciones no gubernamentales (ONGs) en Brasil, así como propósito analizar sus contribuciones sociales y sus prácticas pedagógicas en lo que se refiere a los espacios de educación no formal. En esta dirección, como operación metodológica se realizaron análisis de aportes teóricos a partir de estudios dirigidos al recorrido de las ONGs nacionales y al papel desempeñado socialmente por esas instituciones, así como analizar investigaciones que investigan la actuación de las ONGs en espacios educativos de forma disociada de escenarios escolares, promoviendo, aún así, un ambiente formador. Con esta obra se justifica la elección del objeto de estudio creyendo ser un tema relevante, ya que es posible cuestionar la transferencia estatal de la responsabilidad estatal bajo una concepción de Estado Regulador (BARROSO, 2005), de modo que la se observa el proceso histórico de actuación de esas instituciones, sus objetivos principales en cada contexto, además de presentar la discusión en torno a los diferentes espacios de formación, ya sean formales o informales, escolares o extraescolares (GOHN, 2013). Concluye que las Organizaciones no Gubernamentales actúan en variados espacios con objetivos específicos y que, a pesar de desempeñar un importante papel social, esas instituciones no deben disminuir el papel y el compromiso del Estado con las políticas educativas públicas.

Palabras clave: ONGs; Educación informal; Prácticas pedagógicas; Estado; Sociedad. 


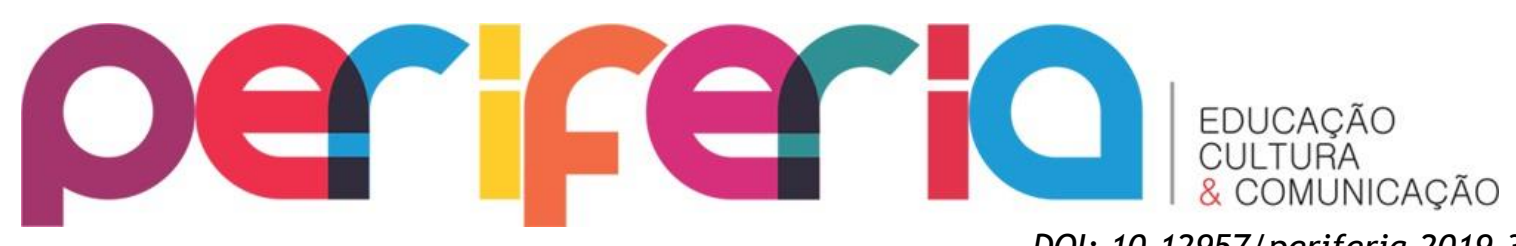

\section{INTRODUÇÃO}

DOI: $10.12957 /$ periferia.2019.34455

O presente texto tem como objetivo apresentar um histórico da trajetória das Organizações não Governamentais (ONGs) no Brasil, bem como analisar suas contribuições sociais, à busca de igualdade de direitos e suas práticas pedagógicas no âmbito da educação informal. Parte do nosso interesse consiste em problematizar o percurso das ONGs e suas especificidades desde a década de 70 , repensando o papel dessas instituições na sociedade, sobretudo, no que diz respeito às ações educativas desse tipo de organização não governamental como educação informal.

Deve ser frisada a relevância dessa pesquisa para o campo educacional e, ainda, destacada a polêmica que envolve as parcerias público/privado em torno da educação formal e informal, suas ações e possíveis contribuições na vida de diferentes grupos sociais que por elas usufruem de projetos, programas, atividades culturais, possibilitando melhoria na qualidade de vida de grupos vulneráveis que por essas instituições são beneficiados.

Para o desenvolvimento da pesquisa foram realizadas leituras referentes à trajetória das ONGs no Brasil, acerca do papel social das mesmas em diferentes contextos e, ainda, um levantamento bibliográfico sobre o desempenho dessas instituições como agentes formadores no âmbito dos espaços educativos não escolares.

Com esta empreitada justificamos a escolha do objeto de estudo acreditando ser um tema relevante, já que é possível questionar a transferência estatal da responsabilidade estatal sob uma concepção de Estado Regulador, observando, deste modo, o processo histórico de atuação dessas instituições, seus objetivos principais em cada contexto, além de apresentar a discussão em torno dos diferentes espaços de formação, sejam eles formais ou informais, escolares ou extra-escolares.

Alguns estudos defendem a ideia de que as ONGs reforçam as desigualdades sociais, suprindo o papel do Estado, fazendo assim, com que o mesmo se ausente de suas funções. Corroboramos dessa linha de pensamento, embora, a partir do estudo realizado termos verificado a potencialidade das ONGs como espaço de formação diante desse cenário de exclusão. Ressaltamos o papel dessas instituições 


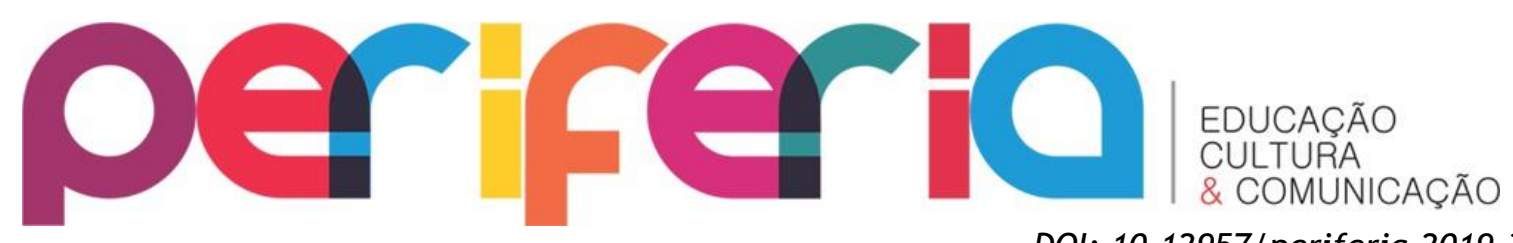

formadoras, que auxiliam no processo de busca autônoma por direitos, principalmente, em áreas menos favorecidas econômica e culturalmente, negligenciadas pelos poderes públicos.

\section{CAMINHANDO POR TEMPOS HISTÓRICOS: A BUSCA PELAS TRAJETÓRIAS DAS ONGs NO BRASIL}

As Organizações não governamentais (ONGs) são instituições desassociadas das esferas públicas, mantidas, recorrentemente, sem auxílio do Estado, sustentada com doações, patrocínios de empresas e trabalho voluntário, atuando na sociedade sem fins lucrativos. Assim, há “ONG” para diferentes frentes de trabalho: ecologia, mulheres, negros, direitos humanos, índios, meninos de rua, portadores do vírus da AIDS, etc. De acordo com Leilah Landim tais “sub-conjuntos” de entidades podem acionar "agentes de gerações, trajetórias, origens, ideários, posições distintas na sociedade - havendo possibilidades de maiores ou menores interseções entre eles, dependendo da área temática” (LANDIM, 1993, p.13).

As ONGs, ao atuarem em variadas causas, também, se caracterizam por solidarizar-se com as classes marginalizadas, estimulando e apoiando esses cidadãos a lutar por seus direitos, contribuindo com a busca pela democracia e igualdade de direitos. Nessa direção,

As ONGs possuem duas características que as diferenciam do amplo conjunto na esfera não estatal: sua finalidade e seu caráter sóciopolítico. Desse modo, constitui-se como organizações: sem fins lucrativos; ou privadas. São 'autogovernadas' com a participação voluntária, além de possuírem finalidade pública e função sóciopolítica (RODRIGUES, 2013, p.3).

Pensando em seu caráter político e ideológico, baseados no entendimento de Elie Ghanem (2012) devemos destacá-las por seu caráter não-governamental, o que permite situá-las como organizações da sociedade civil. Desta feita, compreendemos que sociedade civil e Estado são conceitos que derivam da grande dicotomia dada pela dupla privado e público. Isso pode ser pensado pelo viés interpretativo do Estado enraizado na sociedade, por meio da regulação das relações econômicas, mas 


\section{periferio}

DOI: $10.12957 /$ periferia.2019.34455

também, pela inversão do processo. Ou seja, “por várias formas de participação nas opções políticas e de crescimento das organizações de massa que exercem direta ou indiretamente algum poder político" (BOBBIO, 2000, p. 51).

Segundo Maria da Glória Gohn (2013), nas décadas de 70 e 80, as Organizações não governamentais (ONGs), caracterizavam-se como instituições dispostas a apoiar os movimentos das classes populares, norteando-as na busca pela democratização no Brasil, lutando contra o regime vigente da época; o regime militar. Neste mesmo período, havia por parte das ONGs, a preocupação de reforçar sua identidade e papel social, buscando estabilizar-se cada vez mais. Nesse contexto, estamos nos referindo às nomeadas ONGs cidadãs, que almejavam, frente aos movimentos militantes, novas alternativas, capazes de suprir as necessidades das camadas sociais, como nos aponta Aline Maria Batista Machado:

No período ditatorial, os movimentos sociais foram violentamente reprimidos, pois expressavam um novo modelo de ação social pautado na luta pela mudança do regime político brasileiro e no desejo de construir uma sociedade mais democrática e justa, isto é, com mais liberdade política e igualdade social. Sob o peso das pressões, prisões, torturas e homicídios, as reivindicações dos sujeitos políticos dos movimentos sociais voltados à hegemonia dos setores populares representavam uma ameaça ao sistema capitalista. Por isso tais movimentos tiveram um papel significativo nesse cenário de turbulências, assim como as ONGs que os apoiavam ou assessoravam (MACHADO, 2012, p. 6-7).

No período destacado, as ONGs tinham um papel social de grande influência no comportamento dos cidadãos, no sentido que apontava para os mesmo caminhos para o empoderamento, definido pelas autoras Maria Elisabeth Kleba e Agueda Wendauden como um "processo de mobilizações e práticas que para promover e impulsionar grupos e comunidades na melhoria de suas condições de vida, aumentando sua autonomia" (KLEBA; WENDAUDEN, 2009, p. 735). Mais que o empoderamento, também contribuía na busca de seus direitos e da democratização de maneira geral, propiciando a ascensão de grupos populacionais mais em situação de mais vulnerabilidade por meio de ações coletivas. As ONGs cidadãs tiveram sua parcela de contribuição para a queda do regime militar, na medida em que se tornavam ativamente "comprometidas com o projeto de resistência e denuncia de 


\section{periferio}

DOI: $10.12957 /$ periferia.2019.34455 questões ligadas ao regime ditatorial vigente no Brasil neste período" (ACIOLE, 2008, p. 11).

Em outro contexto, de acordo com Maria da Glória Gohn (2013), na década de 1990, há maior diversidade nesse campo, já que emergem entidades que se autodenominam como terceiro setor, devido sua ligação com empresas e fundações de modo geral, em parceria com as ONGs cidadãs, que tinham um cunho mais ideológico e que, nessa mesma década, diante das mudanças econômicas, modificaram seus moldes de planejamento, dando ênfase ao modo de trabalhar questões pertinentes como gênero, etnia e outras com os considerados excluídos. Porém, com as dificuldades financeiras devido aos desempregos e a violência gerada pela disputa de poder ligado ao tráfico de drogas, passou a ter-se muita resistência por parte da população para participar dos movimentos, que acabam sendo, em sua maioria, patrocinados por empresas privadas, como bancos.

Esta relação está diretamente ligada às novas concepções de Estado, de globalização e de políticas educacionais. Almerindo Afonso (2003) sinaliza a necessidade de repensar e atualizar uma teoria do Estado. Segundo o autor, é importante redefinir a atuação do Estado diante da restruturação do capitalismo a nível global, enfrentando uma suposta divisão de responsabilidades. Não se trata de abandonar o entendimento de Estado moderno analisado nas sociedades democráticas. Mas, concebê-lo como um elemento de um contexto mais amplo de condições, relações e associações políticas que vem sendo estabelecidas.

Para Boaventura Santos (1998) o Estado passou a ser o articulador e que integra um conjunto híbrido de fluxos, redes e organizações em que se combinam e interpenetram elementos estatais e não-estatais, nacionais e globais. Com esse entendimento, observamos que o protagonismo do Estado se mantém, embora a sua centralidade, responsabilidade e visibilidade sociais estejam enfraquecidas. Daí, verificamos uma intensificação de múltiplas participações de instituições privadas, assumindo responsabilidades antes centralizadas nos poderes públicos.

$\mathrm{Na}$ ótica problematizada por Almerindo Afonso (2003), esta descentralização na atuação estatal tem servido para a promoção de novas representações e concepções em torno do bem comum e do espaço público reconhecidas pelo 


\section{periferio}

DOI: $10.12957 /$ periferia.2019.34455

propósito de "quase-mercado" e de "terceiro-setor", levando a um processo que propõe reinventar o Estado como uma associação quase empresarial em um contexto mundial. As políticas educacionais com referência nas ideias citadas podem ser traduzidas, em alguns casos, pela conciliação entre o interesse público, representado pelo Estado, e os interesses privados, representados pelas famílias, outras instituições, serviços e atores locais. Contudo, essa co-responsabilização pode ser problemática e esconder uma nova forma de legitimação da ação do Estado, em um contexto de retração das políticas públicas e dos direitos sociais, econômicos e culturais.

Nessa direção, João Barroso ajuda-nos a pensar a influências das ideias neoliberais destinadas a reduzir a intervenção do Estado na provisão e administração do serviço educativo:

Este "encorajamento do mercado" traduz-se, sobretudo, na subordinação

das políticas de educação a uma lógica estritamente econômica ("globalização"); na importação de valores (competição, concorrência, excelência, etc.) e modelos de gestão empresarial, como referentes para a

"modernização" do serviço público de educação; na promoção de medidas tendentes à sua privatização (BARROSO, 2005, p.741).

Em consonância à problematização trazida por Barroso, Maria da Glória Gohn (2013) propõe pensar que, nesses novos moldes, as ONGs de terceiro setor ${ }^{3}$ lançam mão de estratégias e das novas mídias para a divulgação de seus projetos e, para atrair voluntários, consolida seu capital para que suas ações sejam eficazes e a curto prazo.

Vale a pena ressaltar que as ONGs não devem se encarregar do papel pertencente, constitucionalmente, ao Estado, que seria o que Ana Cynthia Oliveira e Sérgio Haddad denominam como "esvaziamento do papel do estado na área social" (OLIVEIRA; HADDAD, 2001, p.80). A preocupação que se tem, é que as ONGs assumam

\footnotetext{
${ }^{3}$ [...] Não tem perfil ideológico definido, falam em nome de um pluralismo, defendem as políticas de parcerias entre o setor público com as entidades privadas sem fins lucrativos e o alargamento do espaço público não estatal. (GOHN, 2013, p.247)
} 


\section{oe
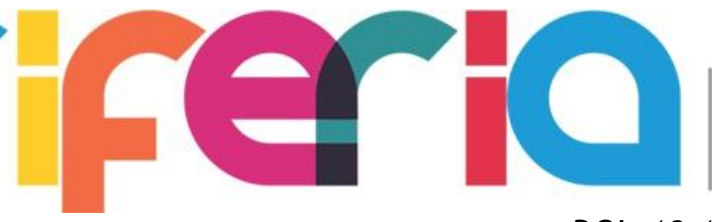 \\ EDUCAÇÃO \\ CULTURA \\ \& COMUNICAÇÃO}

DOI: $10.12957 /$ periferia.2019.34455 uma responsabilidade que compete ao Estado e as demais autoridades públicas, que devem garantir condições básicas aos cidadãos.

É necessário reforçarmos o entendimento de que o direito à educação, por ser um serviço público, ainda que ofertado também pela iniciativa privada, por ser direito de todos e dever do Estado, é obrigação deste interferir no campo das desigualdades sociais e, com maior razão, no caso brasileiro, no terreno das hierarquias sociais, como fator de redução das primeiras e eliminação das segundas, sem o que o exercício da cidadania ficaria prejudicado a priori. Não basta a oferta da educação. Ela deve priorizar o acesso, a permanência e o sucesso escolar. Ela deve voltar-se para a transformação da vida. Sua função social deve embasar-se na igualdade e equidade como pressupostos fundamentais do direito à educação, sobretudo nas sociedades politicamente democráticas e socialmente desejosas de maior igualdade entre as classes sociais e entre os indivíduos que as compõem e as expressam.

Deste modo, compreendemos que as ONGs são apenas mais uma das ações sociais que visam reparar danos causados durante séculos aos grupos sem situações econômicas, culturais e sociais mais vulneráveis. Há conflitos que envolvem o terceiro setor, no sentido de que muitos acreditam que essas atuações reforçam as políticas públicas de ações afirmativas, que na verdade, no nosso entendimento, são compensatórias e baseiam-se em um princípio de equidade. Contudo, por outro lado, há quem reconheça seu papel como mediadora em um dos vários âmbitos de educação informal, ajudando na conscientização da população frente aos problemas sociais, políticos e ideológicos.

Nos estudos envolvendo as redes estabelecidas por essas agências cidadãs, há apontamentos que caracterizam as relações entre Estado e ONGs como "confluência perversa". Mas, o que isso significa. A nosso ver, em conformidade com os fundamentos teóricos analisados, compreendemos que, apesar de possuírem anseios diferentes, essas instituições acabam sendo um dos instrumentos nas mãos do Estado, que visa conseguir por meio dessas parcerias, "a implantação do ajuste neoliberal” (DAGNINO, 2002, p.153 apud MACHADO, 2012, p.3495). 


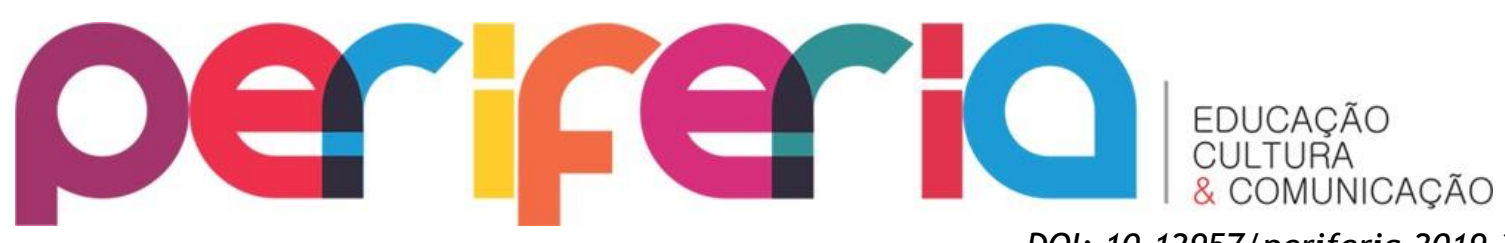

DOI: $10.12957 /$ periferia.2019.34455

O neoliberalismo ligado a educação transforma professores e alunos em reprodutores, máquinas voltadas para o mercado de trabalho, sem expectativas e senso crítico. Partindo desse pressuposto, o que algumas ONGs buscam é, justamente, subsidiar meios para que gerações não se tornem alienadas; alheias aos conflitos sociais ou engessadas pelo modelo de educação formal padronizado e ofertado pelos poderes públicos.

Conforme Andréa Acioli (2008), contemporaneamente, maior parte das ONGs voltam seus olhares às comunidades e as populações carentes, ou ainda, focam em projetos voltados a sustentabilidade e socioambientalismo. Há também as entidades filantrópicas, que não visam nenhum fim lucrativo, e são movidas geralmente, pela caridade e solidariedade.

Tem-se atualmente, com maior convicção por parte das ONGs, a consciência do quão importante é a participação ativa da sociedade nas reivindicações por direitos, luta contra retrocessos, busca por avanços e no que está ligado à tomada de decisões sociais, econômicas e políticas. Se, historicamente, as organizações não governamentais lutam pelos direitos dos grupos vulneráveis supracitados, que durante décadas permaneceram sem voz, atualmente acredita-se no poder da voz dessa mesma classe, transformada em instrumento de busca à igualdade de direitos; a uma sociedade mais democrática, como podemos observar a partir das palavras de Maria da Glória Gohn:

O conceito de sociedade civil atual pressupõe uma participação mais incisiva dos cidadãos na vida pública e no sistema de decisões de política pública via parcerias. Supõe-se, em tese, que existindo esta participação, haverá não só maior controle dos cidadãos sobre as políticas públicas como também maior transparência. Portanto, o conceito contemporâneo de sociedade civil tem na participação cidadã seu principal instrumento de ação e, na democracia, o seu suposto básico (GOHN, 2010, p.11).

Assim, observamos que a participação dos cidadãos, de forma ativa na vida pública, consiste em uma via importante na garantia da efetivação de direitos, desde que a eles não seja transferida a responsabilidade estatal pela garantia dos direitos e da proteção social possibilitada por políticas públicas que visem o reparo das 


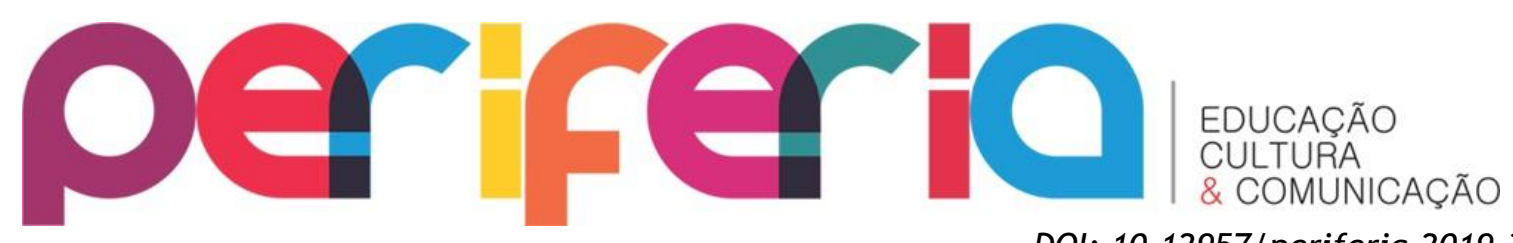

DOI: $10.12957 /$ periferia.2019.34455 injustiças e das desigualdades existentes entre os diferentes grupos de nossa sociedade.

\subsection{PAPEL DAS ONGs:}

Historicamente, um dos papeis desempenhados pelas ONGs está ligado à luta pela igualdade de direitos entre os cidadãos; aos grupos em situação de vulnerabilidade e sem voz ativa na sociedade; sem as mínimas condições de defender-se ou manter-se, propiciando, por meio do que podemos chamar de educação informal, a consciência necessária para sentir-se pertencente ao grupo, capaz de compreender-se como ser que deve cumprir seus deveres e lutar por seus direitos. Trata-se da discussão lançada por Elie Ghanem:

Pelo menos desde o século XIX, organizações não-governamentais sem fins de lucro surgiram com motivações religiosas, políticas, ou ambas, para defender interesses de outros grupos. Frequentemente, isto ocorria porque estes não mostravam ter condições de se defender sozinhos: escravos; crianças; mulheres; povos indígenas; pessoas idosas, desempregadas, deficientes, aditas ao álcool ou com outras doenças mentais e físicas; imigrantes; famílias deslocadas por guerras, não alfabetizadas; pequenos camponeses arruinados; detentos, etc. (GHANEM, 2012, p.52).

Apesar das ONGs partirem de um princípio de equidade, dando oportunidades diferenciadas a esses grupos que viveram por décadas às margens da sociedade brasileira, Ghanem (2012) aborda, criticamente, o fato de que os atos em defesa dessa camada social fragilizada por parte das ONGs podem, por vezes, reforçar esse conceito de vulnerabilidade, impedindo que esses cidadãos atuem autonomamente, reforçando a alienação. "Este caminho é característico da chamada filantropia ou, como veio sendo denominado, do assistencialismo" (GHANEM, 2012, p.52).

Mas, em contrapartida, as ONGs podem intervir de modo de vida daqueles que não são capazes de tomar decisões e/ou não possuem muitas alternativas de atuação na sociedade, ou ainda, agirem em sua própria defesa, passarem a atuar de maneira diferenciada na sociedade, com mais perspectivas sociais. Nessa direção, segundo Oliveira e Haddad (2001), as organizações não governamentais monitoram o Estado 


\section{periferio}

DOI: $10.12957 /$ periferia.2019.34455 de maneira crítica, partindo-se do pressuposto de que almejam o bem comum, em defesa das minorias, por meio de ações afirmativas e oportunidades para todos.

De acordo com Maria da Glória Gohn (2010), diante de todas as mudanças históricas ocorridas no cenário brasileiro, as ONGs cidadãs que resistiram, passaram por vários processos de modificação no que diz respeito ao seu papel na sociedade. Uma delas está ligada ao movimento de intervir diretamente nas questões populares, e não apenas prestar ao povo, o que a autora denomina como assistência. Nessa mesma perspectiva, as informações tornam-se mais acessíveis para todos, o que propicia a democratização do conhecimento.

Outra modificação significativa está relacionada ao foco dos atendimentos. As ONGs passam a voltar seus olhares com mais afinco às mulheres, aos jovens e crianças, buscando condições básicas para uma vida saudável, desde cuidados pessoais até as questões um pouco mais amplas, ligadas diretamente à qualidade de vida em detrimento às assistências primordiais como o saneamento básico, fundamental à saúde. Vale ressaltar, que entre os papeis das ONGs, Gonh delimita “campos de atuação”, sendo eles:

(i) Direitos de Terceira Geração: gênero, meio ambiente (físico, vegetal e animal); direitos humanos, etnias, sexo; Direitos de cidadania, em suma.

(ii) Áreas Sociais básicas: direitos sociais ou de primeira geração: saúde, educação, moradia, alimentação.

(iii) Grupos Sociais clássicos no atendimento da assistência social: crianças, jovens/adolescentes, idosos.

(iv) Área da cultura: clássica (música, dança, literatura, pintura, escultura, teatro e comunicações); diversidades culturais, defesa e preservação do patrimônio histórico e artístico dos povos.

(v) Grupos Vulneráveis e causas sociais: pobreza socioeconômica. (GOHN, 2010, p.13).

Como podemos observar as ONGs desempenham seu papel em campos distintos de atuação. Entretanto, independentemente deste lugar distinto, essas instituições costumam priorizar as inter-relações com os indivíduos que fazem parte do contexto em que elas estão inseridas. Isso acontece porque, além de acompanhar e buscar a igualdade de direitos pensamos que as mesmas estimulam os grupos vulneráveis sujeitos fragilizados, perseguidos ou marginalizados - a procurarem meios de reverter 


\section{periferio}

DOI: $10.12957 /$ periferia.2019.34455 situações conflituosas, motivando-os a serem capazes de compreender as barreiras que os cercam e a unirem-se para revertê-las. Para isso, as mesmas visam aproximar ao máximo desses grupos, conhecendo suas especificidades, pois, desta maneira, declaram buscar e ensinar meios para que elas superem suas fragilidades e se fortaleçam. Célia Regina Pinto (2006) tenta classificar e apontar o suporte oferecido pelas ONGs:

As ONGs podem ser classificadas quanto a seus membros e às causas que defendem em dois grandes grupos: as organizações que defendem a causa de seus membros, formadas por negros contra 0 racismo, ou por mulheres contra o sexismo, ou por gays contra o preconceito em relação à escolha sexual; as que defendem a causa de outros, tais como meninos de rua, sem-teto, drogados, vítimas de abusos contra os direitos humanos, vítimas de abuso sexual, excluídos da cidadania por pobreza ou ignorância etc. Esta é uma característica fundamental destas organizações, pois é a partir das relações que estabelecem com o outro que podemos entender e analisar seu papel e suas funções nas relações sociedade civil-mundo da exclusão e sociedade civil-Estado (PINTO, 2006, p. 657).

Há, ainda, outra entrada possível para se pensar o papel das ONGs. No que diz respeito às instituições com caráter ambientalistas, Pedro Jacobi (2003), afirma que o ponto crucial estabelecido entre elas e a comunidade, no sentido do desenvolvimento de uma postura sustentável, está diretamente ligado à credibilidade que essas agências não governamentais alcançaram ao longo das décadas. Ou seja, há por parte da cidadania, de maneira geral, uma confiabilidade no comprometimento e eficácia destas instituições, sendo assim, torna-se mais fácil intervir e alcançar bons resultados. O autor compreende que para melhores resultados nas questões ambientais, precisa haver conscientização por parte do indivíduo e ela se dá por meio da sensação de pertencimento tanto com o meio que está inserido como com o ambiente e pessoas que o cercam. Veja o que o autor sinaliza:

0 salto de qualidade do ambientalismo ocorre na medida em que se cria uma identidade crescente entre o significado e dimensões das práticas, com forte ênfase na relação entre degradação ambiental e desigualdade social, reforçando a necessidade de alianças e interlocuções coletivas (JACOBI, 2003, p. 201). 


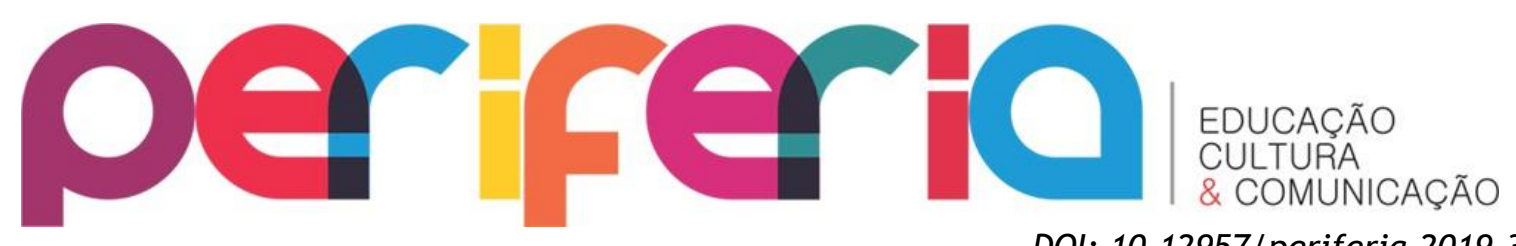

DOI: $10.12957 /$ periferia.2019.34455

Retomando para as análises mais amplas, aquelas estabelecidas por Céli Regina Jardim Pinto (2006) sobre o papel destas instituições, compreendemos que as ONGs associam-se também aos movimentos sociais com a finalidade de possibilitar o surgimento de grupos que pressionem o sistema político. Assim, contemporaneamente, diversos movimentos sociais denominam-se como ONGs. Em contrapartida, alguns procuram apenas estabelecer relações com elas. Cabe ressaltar, que:

$\mathrm{Na}$ relação direta com a sociedade, as ONGs desenvolvem primordialmente projetos de empoderamento, que são na maioria das vezes de dois tipos: projetos que se dirigem a populações excluídas e em risco de marginalização, com o intuito de fortalecer a autoimagem e promover qualificação profissional através de cursos, atividades artísticas e seminários (PINTO, 2006, p. 660).

Partindo dos pontos de vistas e das análises observadas neste estudo, é possível perceber que as ONGs - com as ressalvas necessárias em torno da responsabilidade pública do Estado com as políticas sociais - ocupam importantes espaços de atuação em diferentes campos de ação. Ainda, vale lembrar que as mesmas podem estabelecer relações formais com os poderes públicos, mas, também, é possível reconhecê-las a partir do seu papel informal. É o que apresentaremos a seguir.

\section{AS ONGs E SUAS EXPERIÊNCIAS DE ATUAÇÃO: EDUCAÇÃO FORMAL OU INFORMAL?}

$\mathrm{Na}$ tentativa de compreender as políticas educacionais e a participação estatal em sua implementação, José Gondra e Alessandra Schueler, em 2008, sugerem ampliar o olhar para além da presença do Estado, incluindo, a participação de forças educativas. Para isso, segundo Cíntia Almeida (2018), desnuda-se a existência de disputas de forças distintas pela educação que utilizavam estratégias de poder e se inseriam em um jogo político, social, econômico em prol de um ideário de nação.

No caso brasileiro, principalmente, a partir da segunda metade do século XIX e início do período republicano, a instituição escolar foi legitimada pelo poder 


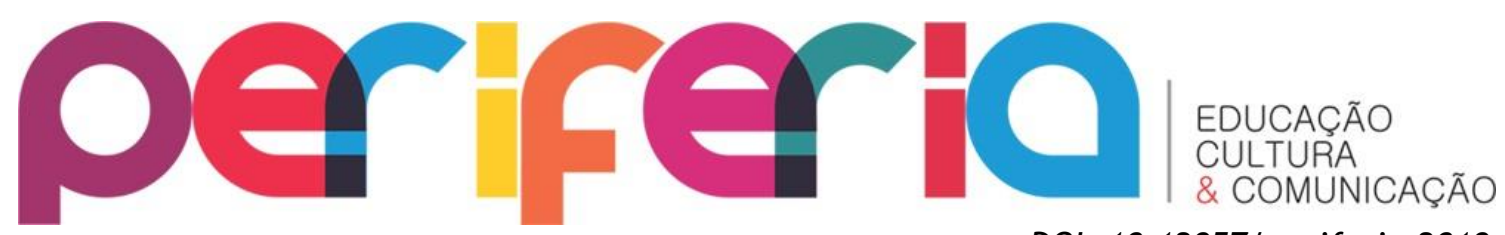

DOI: $10.12957 /$ periferia.2019.34455 público e pela sociedade como um espaço privilegiado, "o mais adequado" para se promover as luzes da instrução. Neste contexto, buscando alcançar a tarefa da “civilidade”, o poder público - com suas ações, leis e projetos em favor da promoção do ensino e da escola - "contou com a força da esfera privada que se destacou por sua atuação no domínio da oferta escolar" (PASCHE, 2014).

Conforme Cíntia Almeida (2018) propõe pensar, observamos na experiência educacional brasileira a criação de múltiplos espaços de educabilidade, espaços educativos não restritos ao escolar. Segundo a autora,

diversos tipos de escolas e práticas educativas surgiram a partir de iniciativas privadas e pelas ações estatais em todo país: escolas públicas, particulares, confessionais, de operários, anarquistas, escolas técnicas para o trabalho na indústria, escolas rurais para o trabalho no campo; ou, ainda, a criação de associações, sociedades e ligas destinadas à educação do povo e sua civilidade, bem como jornais e revistas que cumpriram um papel educativo e serviram como espaços educacionais, de modo a formar ideias, hábitos, e condutas (ALMEIDA, 2018, p.14).

Nessa ramificação e pluralidade de experiências de educabilidade ${ }^{4}$ existentes, entendemos a atuação das ONGs como uma iniciativa a mais para se cumprir um papel educativo. Assim, é possível compreendermos diversas ONGs a partir do campo de atuação caracterizado como educação formal, já que atuam diretamente no oferecimento da educação básica, sustentadas e organizadas por estas instituições, mas, também, por estarem envolvidas em atividades que giram em torno dos domínios escolares, das formas e da cultura escolar ${ }^{5}$ em um panorama geral, apesar de não se realizarem em espaços direcionados ao saber oficial.

\footnotetext{
${ }^{4}$ O termo educabilidade foi investigado por Cíntia Almeida (2018) no sentido de pensar diferentes formas de saberes pedagógicos e escolares socializados pelos mais variados grupos sociais. Importame compreendê-lo a partir de uma profusão de agentes, espaços - institucionais e não institucionalizados -, e, ainda, práticas e saberes que, conjuntamente, compõem experiências de caráter educacional (ALMEIDA, 2018, p.24).

${ }_{5}^{5}$ Pensar a escolar e toda uma cultura que a circunda traz a ideia de que o espaço escolar é uma “instituição de socialização nos tempos modernos" (FARIA FILHO; GONÇALVES; PAULILO; VIDAL, 2004, p. 154). A cultura escolar, segundo os autores citados, deve ser compreendida imbricada com outras instituições que também oferecem a socialização de crianças e jovens. Entre elas, destacamos a família, a Igreja, o mundo do trabalho. Assim sendo, o estudo das práticas escolares enquanto portadoras e formadoras da materialidade do espaço da escola é significativo para o entendimento de uma cultura escolar inserida no processo de constituição de uma sociedade em vias de escolarização.
} 


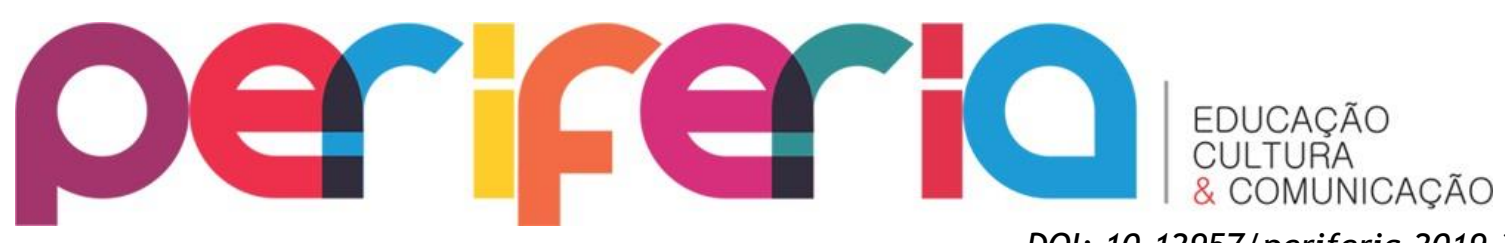

DOI: $10.12957 /$ periferia.2019.34455

Contudo, conforme sugere Elie Ghanem (2012) há, ainda, outras que são identificadas a partir do seu aspecto não formal, mas, que também são reconhecidas a partir das suas experiências educativas, realizando atividades recreativas, culturais, esportivas, eletrônicas e tantas outras.

Organizações da sociedade civil oferecem diretamente serviços educacionais mediante convênios e terceirização ou substituem funções técnicas de órgãos públicos na formação pessoal, na elaboração de materiais de estudo e na formulação de orientações pedagógicas. Ao mesmo tempo, as ONGs com propósitos sedimentados na promoção dos direitos humanos e da democracia procuram contribuir para o redirecionamento e fortalecimento da atuação do Estado em educação. Contudo, quer educando, quer influindo em outras práticas educacionais, o caráter privado das ONGs as coloca no centro de um desafio: a realização do direito à educação (GHANEM, 2012, p. 54).

De acordo com a autora supracitada, as organizações não governamentais podem atuar de maneira paliativa (tentando preencher as lacunas deixadas pelo Estado, procurando suprir as necessidades do povo, sobretudo em cidades rurais, onde a educação pública é muito precária); de maneira inovadora (intervindo por meio de temas como a sustentabilidade, combate de doenças como Aids, e tantos outros temas, que levam sempre em consideração as carências e necessidades do contexto em que estão inseridas; e, ainda, de mudança ou pressão política (mudança: quando uma de suas propostas é atuar em conjunto com a escola pública em prol de melhores resultados; política: quando atuam com programas diretamente ligados ao ambiente político).

Em todos esses casos foi possível observar um discurso apoiado no interesse dessas instituições de propiciar dignidade e maior qualidade de vida a população a quem presta atendimento. Todavia, vale a reflexão de que para uma melhor qualidade de ensino e de vida dos sujeitos envolvidos, há vários fatores que devem ser considerados, de modo que é preciso tensionar e problematizar o papel das mesmas já configurado bastante limitado.

Nessas poucas linhas consideramos as ONGs como um espaço de cooperação às instituições públicas, uma parte ainda pouco representativa das ações que giram 


\section{perferto mageso}

DOI: $10.12957 /$ periferia.2019.34455

em torno do processo educacional, tendo na escola a principal forma de ação educativa. Compreendemos como positiva sua atuação, ainda que devamos enfatizar o alcance reduzido de sua atuação. Isso significar apontar, inclusive, que sua eficácia e aproveitamento exigem mobilização ampla, diálogo constante em torno da tomada de decisões sobre as políticas educacionais implementadas, bem como as definições legais e as práticas diretas executadas nos estabelecimentos educacionais, problematizando, mais uma vez, a importância do reconhecimento e da legitimidade dos espaços formais e informais de educação.

Apesar da legitimidade de sua atuação inferimos que as mesmas não devam funcionar com base em um enfraquecimento da função e atuação dos poderes públicos. Mais do que incitar uma maior participação e proliferação de novas ONGs exercendo um papel educativo, consideramos necessário denunciar a omissão dos poderes públicos frente às políticas educacionais.

As ONGs como experiências de educabilidade são necessárias e importantes. Mas, demasiadamente mais relevantes do que todas elas, trata-se do fortalecimento do papel do Estado no compromisso com os direitos sociais e com as políticas públicas em geral. Para que tais direitos sejam resguardados, com vistas a se garantir um sistema democrático, Norberto Bobbio (2000) defende como caminho para a real democratização de nossa sociedade a ocupação de novos espaços pela população espaços que estão dominados por organizações do tipo hierárquico ou burocrático. Sendo o Estado responsável pelo atendimento das necessidades básicas de sua população, implica discutirmos o seu papel que, conforme aponta o autor, não deve ser reduzido pelas relações de produções capitalistas como parte de dominação. 0 Estado não é apenas um campo de batalha para a luta de classes, ele é o pré-requisito necessário à emancipação humana. Ao cumprir sua função social dentro de uma sociedade democrática, ele permite o ganho e a ampliação de direitos sociais e políticos dentro dele mesmo. 


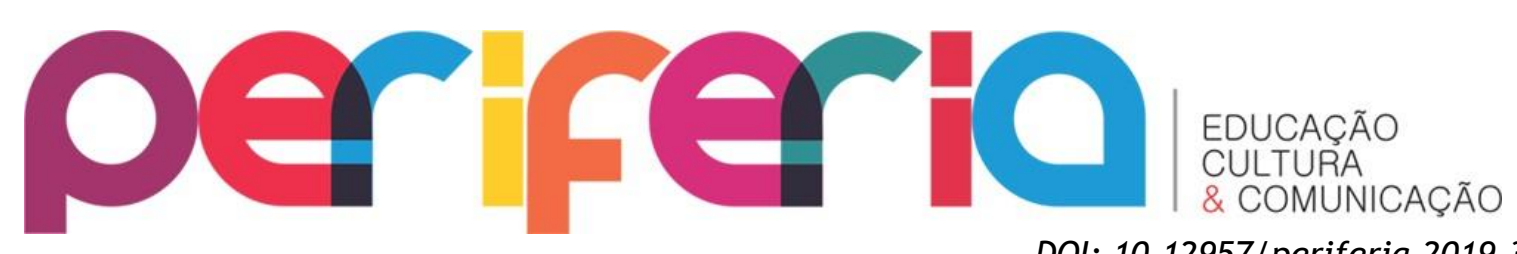

\section{CONSIDERAÇÕES FINAIS}

DOI: $10.12957 /$ periferia.2019.34455

As Organizações não governamentais (ONGs), em sua maioria, são organismos desvinculados dos poderes públicos e possuem cunho ideológico. Tais instituições, conforme relatamos ao longo do estudo, atuam em diversas vertentes, com olhar sensível, sobretudo, para as camadas populares em situação de alta vulnerabilidade, excluídas e prejudicadas historicamente, oferecendo subsídios para a ascensão desses cidadãos, fundamentando-se no princípio de equidade defendido constitucionalmente.

A trajetória percorrida pelas ONGs é marcada por especificidades no que se refere aos objetivos traçados em dados períodos históricos, pois, nenhuma forma de educação, seja ela formal ou informal, é neutra. Logo, avaliamos como necessário pontuar que as sociedades civis tiveram suas ações pautadas em intencionalidade para amenizar problemas existenciais em diferentes contextos sociais e campos de atuação.

Tais instituições não têm a função de ocupar o lugar ou a responsabilidade do Estado. Com suas atuações educativas, a nosso ver, ao contrário disso, devem contribuir com os sujeitos que dela usufruem, propiciando a eles o acesso às práticas educativas direcionadas aos mais variados campos sociais, de modo a potencializar a compreensão do seu papel de cidadãos, ampliando a capacidade crítica de monitorar a responsabilidade estatal com a garantia de políticas públicas para o bem estar social.

De forma específica, a partir da educação, os cidadãos devem refletir e buscar seus direitos na sociedade que também lhes pertence, rompendo estereótipos e princípios neoliberais, um desafio que vem sendo discutido em diferentes contextos, mas que, ainda, contemporaneamente, se faz necessário se problematizar diante do cenário capitalista e das políticas neoliberais, que conduzem a escola pela lógica mercantil, incitando a competividade e eficácia ao invés da integração e distribuição equitativa de um bem comum, um projeto de sociedade.

No que diz respeito à atuação das Organizações Não Governamentais na esfera da educação informal, enquanto o Estado permanece negligenciando a oferta de 


\section{periferio}

DOI: $10.12957 /$ periferia.2019.34455 políticas públicas é válido destacar as políticas e a assistência oferecida por essas instituições. Tais políticas são consideradas como educativas, pois, as mesmas norteiam processos de aquisição do conhecimento, seja para áreas que envolvam os esportes, o mundo artístico e outras formas de expressão, que são primordiais à formação de um ser integral, que estabelece relações, interfere e experimenta a inquietante descoberta do saber. Além disso, contribuem, social e culturalmente, para livrar do ócio uma população em situação mais vulnerável, e, ainda, marginalizada, que por meio desses processos educativos, encontra, por vezes, um espaço de vivência, de atuação, em alguns casos, uma fonte de sobrevivência. Tratase de um espaço de reconhecimento social onde vozes, por muito tempo silenciadas, podem ser ouvidas, onde sujeitos, outras vezes "invisibilizados”, passam a ser vistos e sociabilizados.

\section{REFERÊNCIAS}

ACIOLI, Andréa. A explosão das ONGs no mundo e no Brasil e seus reflexos no espaço rural e fluminense. $4^{\circ}$ ENGRUP: São Paulo, 2008, p. 8-25.

AFONSO, Almerindo Janela. Estado, globalização e políticas educacionais: elementos para uma agenda de investigação. Revista Brasileira de Educação, Jan/Fev/Mar/Abr 2003, n.22, p.35-46.

ALMEIDA, Cíntia Borges de. Um paíz de poucas lettras? Experiências de educabilidade, instrução obrigatória e analfabetismo na "Cidade Maravilhosa" (19001922). Tese (Doutorado em Educação). Universidade do Estado do Rio de Janeiro: UERJ, Rio de Janeiro, 2018.

BARROSO, João. O Estado, a Educação e a Regulação das políticas públicas. Educ. Soc., Campinas, vol. 26, n. 92, Especial - Out. 2005, p. 725-751.

BOBBIO, Norberto. O futuro da democracia: uma defesa das regras do jogo. 7.ed. Rio de Janeiro: Paz e Terra, 2000.

FARIA FILHO, Luciano Mendes de; GONÇALVES, Irlen Antônio; PAULILO André Luiz e VIDAL Diana Gonçalves. A cultura escolar como categoria de análise e como campo de investigação na história da educação brasileira. Revista Educação e Perspectiva, São Paulo, jan./abr. 2004, v. 30, n. 1, p. 139-159.

GHANEM, Elie. As ONGs e a responsabilidade governamental com a escola básica no Brasil. Pro-Posições. Campinas: maio/ago. 2012, v. 23, n. 2 (68), p. 51-65. 


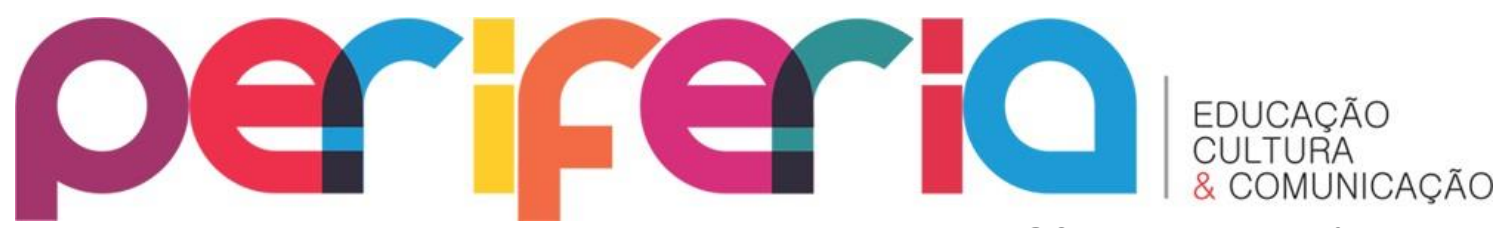

DOI: 10.12957/periferia.2019.34455

GOHN, Maria da Glória. Ações coletivas civis na atualidade: dos programas de responsabilidade/compromisso social às redes de movimentos sociais. Ciências Sociais, Unisinos: São Leopoldo, jan/abr 2010, v. 46, n. 1, p. 10-17.

Sociedade civil no Brasil: movimentos sociais e ONGs. Meta: Avaliação. Rio de Janeiro, mai./ago. 2013, v. 5, n. 14, p. 238-253.

GONDRA, José; SCHUELER, Alessandra Frota. Educação, poder e sociedade no Império brasileiro. SP: Cortez, 2008.

JACOBI, Pedro et al. Educação ambiental, cidadania e sustentabilidade. Cadernos de pesquisa, 2003, v. 118, n. 3, p. 189-205.

KLEBA, M. E.; WENDAUSEN, A. Empoderamento": processo de fortalecimento dos sujeitos nos espaços de participação social e democratização Maternidade Leila Diniz. Saúde em Foco, p. 115-35, 2009.

MACHADO, Aline Maria Batista. O percurso histórico das ONGs no Brasil: Perspectivas e desafios no campo da educação popular. IX seminário nacional de estudos e pesquisas. Paraíba: João Pessoa, 2012.

OLIVEIRA, Ana Cynthia; HADDAD, Sérgio. As organizações da sociedade civil e as ONGs de educação. Cadernos de pesquisa, MAR. 2001, n.112, p. 61-83.

PASCHE, Aline de Morais Limeira. Entre o trono e o altar: sujeitos, instituições e saberes escolares na capital do império brasileiro (1860 a 1880). Tese (Doutorado em Educação). Universidade do Estado do Rio de Janeiro: UERJ, Rio de Janeiro, 2014.

PINTO, Céli Regina Jardim. As ONGs e a política no Brasil: presença de novos atores. Revista de ciências sociais. Rio de Janeiro, 2006, v. 49, n. 3, p. 651-670.

RODRIGUES, Noeli. ONGs: A sociedade civil e o Papel do Estado. Curitiba: UFPR. 2013.

SANTOS, Boaventura de Sousa. Reinventar a Democracia, Lisboa: Gradiva, 1998. 